\title{
Nutritional Status of Under-five Children living in Orphanages compared with their Counterparts living with their Families in Host Communities in Lagos State
}

\author{
Izuka $\mathrm{MO}^{1}$, Olatona $\mathrm{FA}^{2}$ Adeniyi OF${ }^{3}$ Onajole $A T^{2}$
}

${ }^{1}$ Federal Medical Centre, Umuaiha, Abia State

2Department of Community Health and Primary Care, College of Medicine, University of Lagos, Idi-Araba, Lagos, Nigeria

3Department of Paediatrics, College of Medicine, University of Lagos/Lagos University Teaching Hospital, Idi-Araba, Lagos, Nigeria

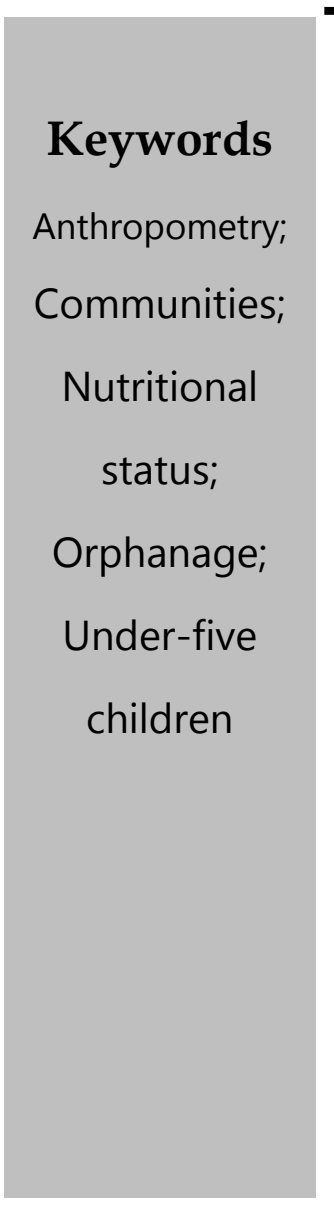

\section{INTRODUCTION}

The United Nations Children's Fund (UNICEF) estimates that there were 140 million orphaned children and adolescents living in the world in year 2015. Though there has been a gradual decline, the rate of

\section{ABSTRACT} communities. status.
Background: The prevalence of malnutrition in Nigerian orphanages is not clearly defined despite the high burden. This study was conducted to determine and compare the nutritional status of children living in orphanages and children living in the host

Methods: It was a comparative cross-sectional study. A multistage sampling technique was used to select 180 under-five children each from orphanages and host communities. A pre-tested questionnaire was used to obtain data on socio-demographic characteristics and nutrient intake. Weight, height, mid-upper-arm circumference and nutrient intake were assessed following standard procedures. SPSS (version 20.0) was used for data entry and analysis. Association between variables was determined using Chi-square, t-test or Fisher's exact tests and level of significance was set at $p<0.05$.

Result: The mean age of the children in orphanages was 38.5 months while that of the children in the host communities was 38.3 months. Wasting and over-nutrition were significantly lower among children living in orphanages compared with those living in the host communities, (5.6\% versus $14.4 \%, \mathrm{p}=0.006)$ and $(5.6 \%$ versus $13.9 \%, \mathrm{p}=0.008)$, respectively. The proportion of children living in orphanages who met the Recommended Dietary Allowance for proteins (95\%) was significantly higher than those in the host communities $(88.9 \%),(p=0.033)$.

Conclusion: The nutritional status of children living in the orphanages was better than that of the children living in their host communities. More interventions on feeding infant and young children are needed in communities in Lagos State to ensure better nutritional

\section{Correspondence to: Dr. F. A. Olatona Department of Community Health and Primary Care, College of Medicine, University of Lagos, Idi-Araba, Lagos, Nigeria Email: folaton@gmail.com Phone number: 08033163216}

reduction has been slow at only $0.7 \%$ per year during the last decade. ${ }^{1}$ Most children who become orphans (an estimated 13.4 million children and adolescents worldwide) had lost one or both parents to Acquired Immune Deficiency Syndrome (AIDS) as at 
2015. More than $80 \%$ of these children (10.9 million) live in sub-Saharan Africa. ${ }^{2}$ Although the total number of orphans from all causes from other parts of the developing world has decreased since 1990, the number from Sub-Saharan Africa has risen by more than $50 \%$. This is because an estimated 12 million (80 per cent) orphans due to AIDS reside in the region. Communities and families in sub-Saharan Africa have been faced with a growing challenge of providing care to these vulnerable children. ${ }^{3}$

Nigeria has one of the highest populations of orphans and vulnerable children (OVC) in the world because of the effect of HIV/AIDS on its large population. ${ }^{4}$ The Joint United Nations Programme on HIV / AIDS (UNAIDS), UNICEF and United States Agency for International Development (USAID) joint report on orphans estimated the total number of orphans from all causes in Nigeria to be 5 million in 1990, 7 million in 2003, and 12 million in 2010.4, 5 This has grave implications for the current and future well-being of the nation. Many families, particularly those headed by grandmothers as the primary caretakers are unable to meet the material needs of the orphaned children in their care. ${ }^{4,5}$

The best way to care for orphans and vulnerable children (OVC) has become a great challenge as their number increases globally. Many of these children are being placed in institutions managed by the government directly or by private entities. Worldwide, the median estimate of children who grow up in institutions is 5.37 million. ${ }^{6}$ Institutional care has become obsolete in developed countries as considerable evidence shows that it is detrimental to the psychosocial wellbeing of children and are not cost effective. However, it is still proliferating in developing countries today as the number of OVC increases due to HIV/AIDS and other social causes. ${ }^{7,8}$

There are problems intrinsic to institutionalized care for OVC which lead to poor psychosocial and cognitive develop-ment. Adequate nutrition is of utmost importance to the growth of children but institutionalized children tend to have poorer nutritional status than children living in communities. Under-nutrition especially in children younger than five years is deleterious to brain growth and development, making them unable to achieve their full genetic development potential. It is also deleterious to their immune-status leading to recurrent and increasing severe infectious illnesses that may ultimately threaten a child's survival. The risk of death from common childhood diseases when compared with the risk of a well-nourished child is double for a mildly malnourished child, tripled for a moderately malnourished child and may even be as high as eight times for a severely malnourished child. 9

The United Nations Children's Fund considers the Nigerian orphan situation as an emergency. The proportion of orphans and rate of orphaning in Nigeria is alarming and the total number of children in orphanages across Nigeria is not clearly 
defined but there are many orphanages in the country. However, Nigeria's Federal Ministry of Women Affairs and Social Development estimates that there are 17.5 million OVC in Nigeria. ${ }^{10}$ Despite the high burden of vulnerable orphans and number of orphanages, the incidence of malnutrition in Nigerian orphanages is not clearly defined. Most studies among institutionalized children have focused on the detrimental effect of institutionalization on their psychological, emotional and cognitive development. Moreover, since the low economic status in Nigeria has negative impact on the nutritional status of all children whether institutionalized or not, it is important to compare the nutritional status of children living in orphanages with those who live with their parents in the communities. However, few studies have critically examined the nutritional status of children in orphanages and compared them with that of children living in their host communities. Nutrition is very vital to a child's physical and cognitive development and these parameters reflect the nutritional support provided by these facilities or families. This study therefore compared the nutritional status of children living in orphanages and children living in the communities.

\section{METHODOLOGY}

The study was a comparative crosssectional study conducted between January and December 2016. The study was conducted in the twenty-seven orphanages spread unevenly across twelve Local Government Areas (LGAs) (Lagos Mainland,
Eti-Osa, Alimosho, Ikeja, Kosofe, Agege, Amuwo-Odofin, Apapa, Ifako-Ijaiye, Ikorodu, Shomolu and Surulere) in Lagos State. (Only twelve out of the twenty LGAs in Lagos State have orphanages) Only one of the twenty-seven orphanages is owned by Lagos State while the rest are private institutions. All the Local Government Areas that host the orphanages are urban LGAs but the host communities vary from highly urbanized communities to semi-urban settlements in Eti-Osa and Ikorodu LGA respectively.

The study was conducted among under-five children living in orphanages and those living with their families in their host communities. All the children below five years who had lived in the orphanages for at least 3 months were recruited into the study. The total number of children underfive years of age in the 27 approved orphanages was 254 . The minimum sample size was determined using the formula for comparing two proportions ( $\mathrm{n}=$ $\left.\left(Z_{\mathrm{a}}+Z_{\beta}\right)^{2}\left[\mathrm{P}\left(100-\mathrm{P}_{1}\right)+\mathrm{P}_{2}\left(100-\mathrm{P}_{2}\right)\right] /\left(\mathrm{P}_{1}-\mathrm{P}_{2}\right)^{2}\right),{ }^{11}$ where $\mathrm{P}_{1}$ was prevalence of underweight among under-five children living in orphanages (19\%) and $\mathrm{P}_{2}$ was the prevalence of underweight among under-five children living in communities (8.5\%). ${ }^{12,} 13$ The minimum sample size calculated was 180 for each study group making a total of 360 .

Purposive cluster sampling technique was used to select the under-five children in the orphanages. Twelve of the orphanages which had the highest number of children were selected purposively out of the twenty- 
seven orphanages and all the children were recruited into the study. Multi-stage sampling technique was used to select the under-five children residing in the host communities. Since the selected orphanages for the research were located in ten communities, all of ten communities were included in the study. (There were two orphanages located in each of AdoLangbasa and Igando-Egan communities to make four orphanages in the two communities; while the remaining 8 communities host one orphanage each: making a total of twelve orphanages in ten communities) Simple random sampling was employed to select three streets from each community to obtain 30 streets. Systematic random sampling was used to select 6 houses from each street. The first house was selected by ballot between the first few houses based on the sampling interval on each street. Thereafter, subsequent houses were chosen based on the sampling interval for each street. Where more than one household lived in a house, one eligible household was selected and where there was more than one child aged less than five years, only one was selected by balloting.

Data was collected using pretested, structured interviewer-administered questionnaire for parents/caregivers of children in each group. The questionnaire was adapted from a validated nutritional status questionnaire from a study designed by Medical Research Institute Sri Lanka in collaboration with UNICEF and World Food Programme. ${ }^{14}$ The questionnaire was pretested in Bola Mofo Zion orphanage in Iju
Agege and the children from Nelson Cole Street in Iju Agege before the commencement of study. Five interviewers with minimum qualification of Ordinary National Diploma (OND) and a nutritionist were trained successfully by the researcher and a nutrition expert on administering the questionnaires and taking anthropometric measurements.

Dietary intake was assessed by 24-hour dietary recall using interviewer method according to the standard technique described by Maziya Dixon. ${ }^{15}$ Dietary intake was obtained for the index child for two days (one-week day and one weekend day) per week and the mean dietary intake was calculated. Care was taken to avoid fasting and festival days while noting the intake. Photographs, food models, measuring spoons, plates and cups were used for quantification of foods. ${ }^{16}$ The dietary intake was converted to nutrient intake using the food composition table for commonly eaten foods and food composition table for West Africa. The mean nutrient and energy intake for each age group were compared with the recommended daily allowance (RDA) for age and sex of the child.

Anthropometric measurements were taken from the children following standard procedures. ${ }^{17}$ Indices were generated using WHO anthropometric software WHO Anthro (version 3, April 2009). The cut-off height for age (HAZ) $z$ scores $<-2 \mathrm{SD}$ ) was used to define stunting or chronic malnutrition, weight for height (WHZ) $z$ score $<-2$ SD was used to define wasting or acute malnutrition 
and underweight was defined as weight for age (WAZ) $z$-score $<-2 \mathrm{SD}$. Body mass index (BMI) was considered low if below $(<)-2 \mathrm{Z}$ score. Overweight was defined as $>+2 \mathrm{SD}$ but $<+3$ SD and Obesity was defined as BMI $\mathrm{Z}$-score $>+3 \mathrm{SD}$. Undernutrition was said to be present when there is any one or any combination of these parameters: (WAZ) was less $(<)-2$ (underweight) or height for age $z$ score $(\mathrm{HAZ})<-2$ (stunting) or $\mathrm{WHZ}<-2$ or BMI Z-score < -2 (wasting). Overnutrition was defined as BMI $Z$ score $>+2 \mathrm{SD}$ and global acute malnutrition a term used to describe acute malnutrition of a group or population was defined as $\mathrm{WHZ}<-2 \mathrm{SD}$ and/or mid-upper arm circumference $(\mathrm{MUAC})<11.5 \mathrm{~cm} .{ }^{18}$ Mid-upper arm circumference was taken following standard procedures. If mid-upper arm circumference was between $11.5 \mathrm{~cm}$ and $12.5 \mathrm{~cm}$, it was regarded as moderate undernutrition, $12.5 \mathrm{~cm}$ and $13.5 \mathrm{~cm}$ as mild undernutrition and any value above $13.5 \mathrm{~cm}$ was considered as being well nourished. ${ }^{19}$ Since MUAC is recommended for use with children between twelve and fifty-nine months of age, the values obtained were not used to determine malnutrition across all age groups.

Data was analyzed using Statistical Package for Social Sciences (IBM SPSS version 22). Measures of central tendency and dispersion were calculated for continuous variables. Mean of the anthropometric measurements and nutrient intake were compared between the two groups of children using T-test. Prevalence of underweight, wasting, stunting, overnutrition and other anthropometric indices were determined and compared using Chisquare analysis and Fishers exact test. The results were considered statistically significant at a $\mathrm{p}$-value $<0.05$. Outcome indicators included the proportion of children with normal anthropometric indices, the proportion of children who met their recommended daily intake for nutrients and energy. Ethics approval was obtained from Health Research and Ethics Committee of the Lagos University Teaching Hospital, Lagos. The approval number is ADM/DCST/HREC/2109. Permission was obtained from the Lagos State Ministry of Youth and Social Development. Written informed consent was obtained from each caregiver and confidentiality was assured. Feedback was provided to the households and orphanages where necessary.

\section{RESULTS}

The mean age of the children living in orphanages was $38.5 \pm 16.4$ months while the mean age of the children living in the host communities was $38.3 \pm 17.2$ months. The highest proportion of the children in both groups; 59 (32.8\%) for children living in orphanages and 53 (29.4\%) for children living in the host communities were within the age group 49 to 60 months. (Table 1 ) The mean age of the caregivers of the children living in orphanages, $(34.79+7.1)$ years was significantly higher than the mean age of the caregivers of the children living in host communities $(32.26+6.31)$ years $(p=0.01)$; however, there was no statistically significant difference between their educational levels $(p=0.861)$. 
Table 1: Socio-demographic characteristics of the children

\begin{tabular}{|c|c|c|c|c|}
\hline Variables & Orphanages & Communities & & \\
\hline & $\begin{array}{l}\text { Frequency } \\
(\mathrm{n}=180) \\
\mathrm{n}(\%)\end{array}$ & $\begin{array}{l}\text { Frequency } \\
(\mathrm{n}=180) \\
n(\%)\end{array}$ & $\mathbf{x 2}$ & $p$-value \\
\hline \multicolumn{5}{|l|}{ Age group (months) } \\
\hline $0-12$ & $18(10.0)$ & $19(10.6)$ & 1.289 & 0.863 \\
\hline $13-24$ & $24(13.3)$ & $31(17.2)$ & & \\
\hline $25-36$ & $38(21.1)$ & $38(21.1)$ & & \\
\hline $37-48$ & $41(22.8)$ & 39 (21.7) & & \\
\hline $49-60$ & $59(32.8)$ & $53(29.4)$ & & \\
\hline Mean age \pm SD (months) & $38.5+16.4$ & $38.3+17.2$ & $t=0.113$ & 0.91 \\
\hline \multicolumn{5}{|l|}{ Sex } \\
\hline Female & $92(51.1)$ & $101(56.1)$ & 0.905 & 0.342 \\
\hline Male & $88(48.9)$ & 79 (43.9) & & \\
\hline
\end{tabular}

Table 2: Comparison of anthropometry between children living in orphanage and those within the host communities

\begin{tabular}{lllll}
\hline Anthropometry & $\begin{array}{l}\text { Orphanage } \\
\text { Mean + SD }\end{array}$ & $\begin{array}{l}\text { Community } \\
\text { Mean + SD }\end{array}$ & T-test & $\boldsymbol{p}$-value \\
\hline Weight $(\mathrm{kg})$ & $13.98+4.06$ & $13.51+3.97$ & 1.13 & 0.258 \\
Height $(\mathrm{cm})$ & $94.29+14.6$ & $91.94+14.1$ & 1.55 & 0.121 \\
Body Mass Index $\left(\mathrm{kg} / \mathrm{m}^{2}\right)$ & $15.47+1.7$ & $15.96+3.39$ & 1.72 & 0.085 \\
MUAC $(\mathrm{cm})$ & $14.7+1.5$ & $16.13+1.28$ & 9.02 & 0.001 \\
Weight-for-Height Z scores & $-0.24+1.2$ & $-0.13+1.3$ & -0.83 & 0.405 \\
Weight-for-Age Z scores & $-0.34+1.3$ & $-0.61+1.3$ & 1.97 & 0.050 \\
BMI-for-Age Z scores & $-0.18+1.3$ & $-0.02+1.3$ & -1.17 & 0.244 \\
Height-for-Age Z scores & $-0.34+1.7$ & $-0.96+1.4$ & 3.78 & 0.001 \\
MUAC Z scores & $-0.75+1.1$ & $0.31+0.9$ & -4.15 & 0.001 \\
\hline
\end{tabular}

$\mathbf{S D}=$ Standard Deviation, $\mathrm{Kg}=$ kilograms, $\boldsymbol{m}^{2}=$ metre squared, $\mathrm{cm}=$ centimeters

The mean of the mid upper arm circumference $14.7(\mathrm{SD} \pm 1.5) \mathrm{cm}$ of the children living in orphanages was significantly lower than $16.13(\mathrm{SD} \pm 1.28) \mathrm{cm}$ of the children living in communities $(p=0.001)$. The weight for age $Z$ score of children living in children living in orphanages was significantly lower than $0.34+1.3 \mathrm{~cm}$ of the children living in communities $0.61+1.3(p=0.05)$. (Table 2$)$ prevalence of wasting was significantly lower among children living in orphanages $10(5.6 \%)$ compared with those living in host communities 26 (14.4\%), ( $p=0.006)$. The prevalence of stunting was significantly lower among children living in orphanages $24(13.3 \%)$ compared with those living in host communities 38 (21.1\%), ( $\mathrm{p}=0.05)$. Over-nutrition was significantly higher among children living in communities 25 (13.9) compared with those living in orphanages 10 (5.6\%). ( $p=0.008)$ (Table 3) The mean daily calories intake (1114.33+ $286.5) \mathrm{kcal}$, proteins $(31.48+14.9) \mathrm{g}$ and fat $(36.37+14.9) \mathrm{g}$ among children living in 
Table 3: Comparison of nutritional status of children living in orphanages and those living in host communities

\begin{tabular}{lllll}
\hline Nutritional status & $\begin{array}{l}\text { Orphanage } \\
\text { n (\%) }\end{array}$ & $\begin{array}{l}\text { Community } \\
\text { n (\%) }\end{array}$ & $\mathbf{x}^{\mathbf{2}}$ & $\boldsymbol{P}$-value \\
\hline Normal & $119(66.1)$ & $71(39.4)$ & 25.68 & $0.00001^{*}$ \\
Underweight & $21(11.7)$ & $26(14.4)$ & 0.61 & 0.434 \\
Stunting & $24(13.3)$ & $38(21.1)$ & 3.81 & 0.051 \\
Wasting & $10(5.6)$ & $26(14.4)$ & 7.41 & 0.006 \\
Overweight & $6(3.3)$ & $16(8.9)$ & 4.84 & 0.027 \\
Obese & $0(0)$ & $3(1.7)$ & 3.02 & $0.247^{*}$ \\
Wasting and Stunting & $32(17.7)$ & $56(31.1)$ & 8.60 & 0.003 \\
Undernutrition & $41(22.8)$ & $56(31.1)$ & 3.17 & 0.075 \\
Over-nutrition & $10(5.6)$ & $25(13.9)$ & 7.12 & 0.008 \\
\hline
\end{tabular}

*Fishers exact $\mathbf{S D}=$ Standard Deviation, $\mathrm{cm}=$ centimeters, $x 2=$ chi squared

orphanages were significantly higher than the daily mean calories $(1047.85+327.8)$, protein $(25.19+10.8)$ and fat intake $(30.89$ +15.39 ) of the children living in the communities. $(p=0.041)$ The mean daily intake of all the minerals and vitamins except for vitamin B1 of the children in orphanages were higher than those of the children in the communities. $(p=0.001)$ (Table 4)

The proportions of children living in orphanages who met the recommended dietary allowance for carbohydrates 87 (48.9\%) and protein 171 (95.0\%) were significantly higher compared with those living in communities. \{68 (38.6\%) and 160 $(88.9 \%)\}$ respectively $)(\mathrm{p}=0.052, \quad \mathrm{p}=0.033$ respectively) (Table 5)

\section{DISCUSSION}

This study compared the nutritional status of under-five children residing in orphanages with children of the same age living with their families in the host communities of these orphanages in Lagos.
There was no significant difference between the ages, sex, mean weight, height, BMI among the two groups of children. The prevalence of stunting in this present study was higher among children living in the community than those living in orphanages. However, in Kenya and Jamaica the prevalence of stunting and underweight among orphanage children were significantly higher than the prevalence obtained among children in the communities. ${ }^{20}, 21$ Stunting is caused by long-term deficiency of nutrient intake and frequent infections. It is a marker of chronic malnutrition which subsequently has significant effect on the cognitive development and other aspects of growth in children. The children living in the orphanages in Lagos probably had better access to adequate and nutritious food from early life since orphanages enjoy donations and funding to purchase foods by different organizations which the parents living in host communities might not have access to. 
Table 4: Mean daily energy, macronutrients and micronutrient intake among orphanage children and children in communities

\begin{tabular}{lllll}
\hline Calories/Nutrient & $\begin{array}{c}\text { Orphanage } \\
\text { (n= 180) } \\
\text { Mean } \pm \text { SD }\end{array}$ & $\begin{array}{c}\text { Community } \\
\text { (n= 180) } \\
\text { Mean } \pm \text { SD }\end{array}$ & T-test & p-value \\
\hline Calories (kcal/kg/day) & $1114.33 \pm 286.5$ & $1047.85 \pm 327.8$ & 2.04 & 0.041 \\
Carbohydrates (g/d) & $128.92 \pm 35.6$ & $123.92 \pm 46.1$ & 1.24 & 0.213 \\
Protein (g/kg/d) & $31.48 \pm 13.4$ & $25.19 \pm 10.8$ & 4.88 & 0.001 \\
Fat (g/d) & $36.37 \pm 14.9$ & $30.89 \pm 15.39$ & 3.42 & 0.001 \\
Vitamin A (ug/d) & $974.01 \pm 1019.43$ & $816.70 \pm 759.8$ & 1.66 & 0.098 \\
Vitamin C (mg/d) & $29.37 \pm 28.3$ & $26.60 \pm 33.1$ & 0.85 & 0.394 \\
Vitamin B1 (mg/d) & $0.61 \pm 0.27$ & $0.65 \pm 0.34$ & 1.12 & 0.260 \\
Vitamin B2 (mg/d) & $0.84 \pm 0.36$ & $0.75 \pm 0.30$ & 2.76 & 0.006 \\
Vitamin B3 (mg/d) & $7.05 \pm 2.93$ & $6.78 \pm 3.23$ & 0.84 & 0.400 \\
Vitamin B6 (mg/d) & $0.58 \pm 0.23$ & $0.51 \pm 0.31$ & 2.49 & 0.013 \\
Vitamin B12 (ug/d) & $1.57 \pm 0.86$ & $1.33 \pm 0.60$ & 3.05 & 0.002 \\
Folate (ug/d) & $173.93 \pm 77.17$ & $162.48 \pm 77.55$ & 1.40 & 0.161 \\
Calcium (mg/d) & $595.72 \pm 393.1$ & $524.85 \pm 131.1$ & 2.22 & 0.023 \\
Iron (mg/d) & $7.97 \pm 3.1$ & $7.56 \pm 4.6$ & 0.99 & 0.324 \\
Magnesium (mg/d) & $115.77 \pm 63.7$ & $101.37 \pm 35.1$ & 2.65 & 0.008 \\
Potassium(g/d) & $1459.88 \pm 409.2$ & $1040.37 \pm 445.8$ & 9.30 & 0.001 \\
Phosphorus (mg/d) & $690.82 \pm 305.4$ & $596.83 \pm 247.9$ & 3.20 & 0.001 \\
Sodium (g/d) & $2054.11 \pm 2295.1$ & $1009.94 \pm 823.5$ & 57.95 & 0.001 \\
Zinc (mg/d) & $4.23 \pm 2.0$ & $4.02 \pm 1.7$ & 1.03 & 0.305 \\
\hline
\end{tabular}

Kg= kilograms, $g=$ grams, $d=$ day, $u g=$ micro gram

Table 5: Comparison of children that met their recommended dietary allowance for macro and micronutrients

\begin{tabular}{lllll}
\hline Calories/nutrient & $\begin{array}{l}\text { Orphanage } \\
\text { (n= 180) } \\
\mathbf{n}(\%)\end{array}$ & $\begin{array}{l}\text { Community } \\
\text { (n= 180) } \\
\mathbf{n ~ ( \% ) ~}\end{array}$ & x2 & p-value \\
\hline Calories & $89(49.4)$ & $71(39.4)$ & 3.645 & 0.056 \\
Carbohydrates & $87(48.9)$ & $68(38.6)$ & 3.77 & 0.052 \\
Protein & $171(95.0)$ & $160(88.9)$ & 4.53 & 0.033 \\
Vitamin A & $116(64.4)$ & $130(72.2)$ & 2.51 & 0.113 \\
Vitamin C & $71(39.4)$ & $54(30.0)$ & 3.54 & 0.06 \\
Vitamin B1 & $106(58.9)$ & $105(58.3)$ & 0.01 & 0.915 \\
Vitamin B2 & $145(80.6)$ & $136(75.6)$ & 1.31 & 0.252 \\
Vitamin B3 & $80(44.4)$ & $75(41.7)$ & 0.283 & 0.595 \\
Vitamin B6 & $77(42.8)$ & $60(33.3)$ & 3.4 & 0.065 \\
Vitamin B12 & $129(71.7)$ & $113(62.8)$ & 3.22 & 0.072 \\
Folate & $90(50.0)$ & $75(41.7)$ & 2.51 & 0.113 \\
Calcium & $53(29.4)$ & $39(21.7)$ & 2.86 & 0.091 \\
Iron & $59(32.8)$ & $74(41.1)$ & 2.68 & 0.101 \\
Magnesium & $101(56.1)$ & $87(48.3)$ & 79.71 & 0.14 \\
Phosphorus & $159(88.3)$ & $149(82.8)$ & 2.24 & 0.134 \\
Potassium & $18(10.0)$ & $22(12.2)$ & 0.45 & 0.502 \\
Sodium & $158(87.8)$ & $169(93.9)$ & 4.03 & 0.045 \\
Zinc & $94(52.2)$ & $111(61.7)$ & 3.27 & 0.07 \\
\hline
\end{tabular}

Wasting on the other hand is usually a marker of acute malnutrition. It can also result from infections that are associated with diarrhea. The prevalence of wasting in this study was significantly lower among children living in orphanages compared with those living in communities ( $\mathrm{p}=0.006)$. The findings obtained from a similar study among under five children in Brong Ahafo region of Ghana, in year 2018 showed no 
difference in the prevalence of stunting and wasting among the children in the orphanages and host communities in the region. ${ }^{22}$ On the other hand, a similar study among primary school children in Dagoretti division, Nairobi, Kenya in year 2014 showed higher rates of underweight and stunting among children living in orphanages compared with children living in their host communities 20 The higher rates obtained in Dagoretti division, Nairobi, Kenya might be because the study was conducted among a different age group.

In this present study, the prevalence of stunting (13.3\%) and wasting (5.6\%) among children living in orphanages were much lower than the reports obtained in a previous study among children living in orphanages in Lagos, where $60.6 \%$ were wasted, $55.9 \%$ were underweight, $62.3 \%$ were stunted, $5.4 \%$ were overweight and $3.5 \%$ were obese. ${ }^{23}$ This present prevalence of stunting and wasting is also much lower than the regional average for south-western region of Nigeria $(22.0 \%$ and $10.0 \%)$ and the national average for Nigeria $37.0 \%$ and $18.0 \%)$, respectively. ${ }^{24}$ The reason for these differences may be related to differences in availability of food, infant feeding knowledge and practices amongst the caregivers of the children in the orphanages. In this study, the caregivers of the children living in orphanages were significantly older than the caregivers of the children in the communities and comprised of women in and beyond the reproductive age group. Their ages, infant feeding knowledge, experience and expertise in feeding practices might have influenced their feeding practices. The caregivers of the children in the communities were mainly mothers who were younger and often less experienced in child care practices. The children in orphanages faring better than the children living in communities depict that those children are well cared for compared to the past when OVC were neglected and fared worse than other children.

There are conflicting reports on the prevalence of malnutrition in children in orphanages outside Lagos State in Nigeria and other parts of world. The prevalence of stunting was $75.0 \%$ among children in ten orphanages in Benin City, Nigeria which is far above the national average of $37.0 \%$ as shown in National Demographic Health Survey. 24, 25 In another study in Abuja municipality the prevalence of stunting, wasting and underweight among the orphanage children were as high as $63.0 \%$, $47.5 \%$ and $45.5 \%$ respectively. ${ }^{26}$ However, in Owerri, the prevalence of stunting (34\%) and wasting $(18 \%)$ were much lower among orphanage children compared to their counterparts living in communities. ${ }^{27}$ The findings from Owerri were similar to the national average estimates for both chronic and acute malnutrition, but higher than the regional average for south eastern state for stunting $(22.0 \%)$ wasting $(12.0 \%)$. The relatively low level of stunting and underweight among children living in orphanages in this study is similar to the findings among children living in orphanage in Ghana. ${ }^{22}$ Reports from Kenya also 
showed significantly lower prevalence of wasting among children living in orphanages compared to children living in the communities. ${ }^{20}$ The varying reports could be a reflection of how the children are cared for in different settings.

The higher prevalence of wasting and stunting among children living in communities might be an indication of the prevalent poverty, inadequate care especially inappropriate feeding of infant and young children in the communities compared to the institutionalized children who are cared for by Non-governmental organizations who receive funding from different donors. All the children living in orphanages except the infants are given the same diet, unlike children living in the communities who would be given varied diets based on varied socioeconomic classes.

Over-nutrition was significantly higher among children living in the communities making a greater proportion of these children to be at the extremes of weight compared to the children living in orphanages. This confirms the existence of the double burden of malnutrition in developing countries such as Nigeria. The same group of children who suffer wasting also suffer over-nutrition. According to Baker's thrifty phenotype hypothesis, defi ciency of nutrients during the antenatal stage and early life followed by an improvement in nutritional availability later, causes an increased risk of metabolic disorders, including obesity and Type II diabetes, as a result of permanent changes in the metabolic processing of glucoseinsulin determined in utero. ${ }^{28}$ Therefore, the higher levels of undernutrition among the children living in the communities might explain the higher levels of over-nutrition among them.

The children living in orphanages had significantly higher mean calories, proteins, fat, minerals and vitamins (except vitamin B1) intake compared to their counterparts living in the communities. $(p=0.041),(p=$ 0.001). The proportions of children living in orphanages who met the recommended dietary allowance for carbohydrates and protein were also significantly higher than those living in the orphanages. $(\mathrm{p}=0.052$, $p=0.033)$. This indicates that the children living in orphanages in Lagos received more nutrients than their counterparts living in communities. Macro and micro-nutrients are important for growth and development. The inadequate nutrition among children living in communities can explain the higher rates of stunting and wasting among those children.

Poor nutrient intake among under 5 children living in communities has been documented by earlier studies in this region. 29,30 However, similar studies in Ghana and Kenya had divergent results, showing that under five children in orphanages received less macro and micro nutrients compared to their counterparts living in communities. 22 , 31-33 While some studies have shown a consistent failure of the children living in orphanages to meet the 
recommended dietary allowance for micro nutrients, a few has shown high proportion of such children meeting their recommended dietary allowance for both macro and micronutrients. This implies that being orphans is not synonymous with poor nutrition. The nutritional status of orphans depends on the availability of food and care in the settings where they live.

Limitations of the Study: The age at entry and the duration of stay of the children living in the orphanages were not obtained. The information would have been useful in exploring factors associated with the nutritional status of the children.

Conclusion: The nutritional status of children living in the orphanages was better than that of the children living in their host communities. Measures to improve household food security such as alleviation of poverty, sustainable agricultural systems and improving employment opportunities for women should be put in place in Lagos State while caregivers of under-five children should be trained on feeding infant and young children to ensure better nutritional status.

\section{REFERENCES}

1. United Nations Children's Fund for every child. Orphans. [cited November 8, 2020] Available from: URL: https://www.unicef.org/media/orphans \#.

2. United Nations Children's Fund, Towards an AIDS-Free Generation Children and AIDS: Sixth Stocktaking Report, 2013, UNICEF, New York, 2013. [cited November 10, 2020] Available from: URL: https://www.unaids.org/sites/default/f iles/media_asset/20131129_stocktakin g_report_children_aids_en_0.pdf.

3. Kidman R, Thurman TR. Caregiver burden among adults caring for orphaned children in rural South Africa. Vulnerable children and youth studies. 2014; 9(3): 234-246.

4. Oladokun R, Brown B, Aiyetan P, Ayodele O, Osinusi K. Comparison of socio-demographic and clinical characteristics of orphans and nonorphans among HIV-positive children in Ibadan, Nigeria. Int J Infect Dis. 2009; 13(4): 462-468. doi: 10.1016/j.ijid.2008.08.017.

5. Embleton, L, Ayuku, D, Kamanda, A, Atwoli L, Ayaya S, Vreeman $\mathrm{R}$ et al. Models of care for orphaned and separated children and upholding children's rights: cross-sectional evidence from western Kenya. BMC Int Health Hum Rights 2014; 14:9 [cited November 10, 2020] Available from: URL: https://doi.org/10.1186/1472-698X14-9.

6. Desmond C, Watt K, Saha A, Huang $\mathrm{J}, \mathrm{Lu} \mathrm{C}$. Prevalence and number of children living in institutional care: global, regional, and country estimates. Lancet Child Adolescent Health. 2020; [cited December 5, 2020] Available from: URL: https://doi.org/10.1016/S23524642(20)30022-5.

7. Wanat S, Whisnant J, Reicherter $\mathrm{D}$, Solvason B, Juul S, Penrose B, Koopman C. Coping with the challenges of living in an Indonesian residential institution. Health Policy. 2010; 96(1):45-50. doi: 10.1016/j.healthpol.2010.01.001.

8. Sadik A. Orphanage children in Ghana: Are their dietary needs met? Pakistan Journal of Nutrition 2010; 9(9): 844-852.

9. Akorede QJ, Abiola OM. Assessment of nutritional status of under five children in Akure South Local Government, Ondo State, Nigeria, International Journal of Recent Research and Applied Studies. 2013; 14(3): 671-681.

10. USAID. Review of Programming for Orphans and Vulnerable Children in Nigeria: Exploring Opportunities for Future Investments in Nutrition Social and Behavior Change Communication. 
[cited December 5, 2020] Available from: URL: https://www.springnutrition.org/publications/reports/revie w-programming-orphans-andvulnerable-children

11. Prabhakara GN. Sample Size Determination. Textbook on Biostatistics. Jaypee Brothers Medical Publishers LTD. 2006; 11:110.

12. Obiakor-Okeke NP, Nnadi BC. Nutritional status, caregiving and feeding practices of infant and pre-school children (0-5 years) in motherless babies' homes in Owerri metropolis. Journal of Biology, Agriculture and Healthcare. 2014; 4(17): 190-198.

13. Akorede QJ, Abiola OM. Assessment of Nutritional status of under-five children in Akure South Local Government, Ondo State, Nigeria. International Journal of Recent Research and Applied Studies. 2013; 14(3): 671-681.

14. Jayatisa R, Hossain M, Nanayakkara L. Assessment of nutritional status and associated factors in Northern Province of Sri Lanka. Ministry of health Sri Lanka, UNICEF, WFP; 2012.

15. Maziya-Dixon B, Akinyele IO, Oguntona EB, Nokoe S, Sanusi RA, Harris, E. National food consumption and Nutritional Survey 2001-2003. Summary IITA, Ibadan Nigeria. 2006; 10-33.

16. Fifteenth annual report of the Department of health, National Health Scheme. Food Portions Book, NHS Bristol 2005.

17. Gibson RS. 2005. Measuring Food Consumption of Individuals. Principles of Nutritional Assessment. Oxford University Press. New York. 41-46 pp.

18. World Health Organization. Training Course on Child Growth Assessment. Geneva,

WHO, 2008. [cited November 1, 2017]

Available from: URL

https://www.who.int/childgrowth/train ing/module_h_directors_guide.pdf

19. Mother and Child Nutrition. Early detection and referral of children with malnutrition.

Interpretation of Mid-Upper Arm Circumference, MUAC indicators. [cited December 9, 2020] Available from: URL https://motherchildnutrition.org/earlymalnutrition-detection/detectionreferral-children-with-acutemalnutrition/interpretation-of-muacindicators.html.

20. Mwaniki EW, Makokha AN. Nutrition status and associated morbidity risk factors among orphanage and nonorphanage children in selected primary schools within Dagoretti Division, Nairobi, Kenya. East African Medical Journal 2014; 91(9): 289-297.

21. Nelson RG. Residential context, institutional alloparental care, and child growth in Jamaica. Am J Hum Biol. 2016; 28(4): 493-502. doi:10.1002/ajhb.22819.

22. Ali Z, Abu N, Ankamah, IA, Gyinde EA, Seidu AS, Abdul-Razak A. Nutritional status and dietary diversity of orphan and non-orphan children under five years: a comparative study in the Brong Ahafo region of Ghana. BMC Nutr. 2018; 4: 32. [cited November 10, 2017] Available from: URL https://doi.org/10.1186/s40795-0180240-0.

23. Adeomi AA, Aliyu MS, Sabageh AO. Eating patterns, dietary diversity and the nutritional status of children residing in orphanages in Southwestern Nigeria. J Nutr Health Sci 2019; 6(2): 202. [cited November 10, 2020] Available from: URL: https://bettercarenetwork.org/sites/def ault/files / 201911/ab5674be6d0c277dd 981d8664e752573374f.pdf.

24. National Population Commission (NPC) [Nigeria] and ICF International. Nigeria Demographic and Health Survey 2013. Abuja, Nigeria, and Rockville, Maryland, USA: NPC and ICF International. 2014.

25. Nwaneri DU, Sadoh AE. Assessment of facilities and best practices in orphanages in Benin City, South-South Region, Nigeria. Journal of Community Medicine and Primary Health. 2016; 28(2): 69-76.

26. Steve-Edemba CL. Assessment of the feeding practices, vitamin A, iron, zinc and anthropometrics status of underfive children in orphanages of federal capital territory Abuja, Nigeria. [Master thesis]. University of Nigeria, Nsukka, 2012. [cited September 12, 2020] Available from: URL: 
http://repository.unn.edu.ng:8080/.../ steveedemba\%20chizoba\%20lilian.pdf

27. Obiakor-Okeke NP, Nnadi BC. Nutritional status, care giving, and feeding practices of infants and preschool children (0-5 years) in motherless babies' homes in Owerri Metropolis. Journal of Biology, Agricultural and Healthcare. 2014; 4(17): 190-198.

28. Hales, CN; Barker, DJP. The thrifty phenotype hypothesis: Type 2 diabetes. British Medical Bulletin. 2001); 60(1): 5-20. [cited July 20, 2020] Available from: URL: https://doi:10.1093/bmb/60.1.5. PMID 11809615.

29. Owoaje E, Onifade O, Desmennu A. Family and socioeconomic risk factors for undernutrition among children aged 6 to 23 months in Ibadan, Nigeria, Pan Afr Med J. 2014; 17: 161. [cited June 12, 2016] Available from URL: https://doi:10.11604/pamj.2014.17.16 1.2389

30. Senbanjo IO, Olayiwola IO, Afolabi WA, Senbanjo OC. Maternal and child undernutrition in rural and urban communities of Lagos state, Nigeria: the relationship and risk factors. BMC Research Notes 2013; 6:286. [cited March 9, 2017] Available from URL:https://doi.org/10.1186/17560500-6-286

31. Mwaniki EW, Makokha AN. Nutrition status of children in orphanages in selected primary schools within Dagoretti Division Nairobi, Kenya. J Nutr Food Sci. 2013; 4: 248. [cited March 19, 2017] Available from URL: https://doi: 10.4172/2155-9600.1000248.

32. Vaida N. Nutritional status of children living in orphanages in District Budgam. J\&K International Journal of Humanities and Social Science. 2013; (2)2: 36-41.

33. Serere JH, Zengeni $P$, Usai $T$, Chinofunga D, Nyamunda BC. Adequacy of nutritional levels at local orphanage homes. International Journal of Scientific Engineering and Research 2013; 1(1): 19-23. 